\title{
Purified polysaccharide from Ginkgo biloba leaves inhibits P-selectin-medi- ated leucocyte adhesion and inflammation ${ }^{1}$
}

\author{
Rui $\mathrm{FEI}^{2,3}$, Yu FEI ${ }^{4}$, Sheng ZHENG ${ }^{2}$, Yan-guang GAO ${ }^{2}$, Hong-xia SUN ${ }^{5}$, Xian-lu ZENG ${ }^{2,6}$ \\ ${ }^{2}$ Institute of Genetics and Cytology, Northeast Normal University, Changchun 130024, China; ${ }^{3}$ Department of Cell Biology, School of Norman \\ Bethune Medical Science, Jilin University, Changchun 130021, China; ${ }^{4}$ Department of Cardiology, Second Hospital, Jilin University, \\ Changchun 130041, China; ${ }^{5}$ Department of Thoracic/Head and Neck Medical Oncology, The University of Texas MD Anderson Cancer \\ Center, Houston Texas 77030, USA
}

\section{Key words}

polysaccharides of Ginkgo biloba leaves; cell adhesion inhibition; inflammation; Pselectin

${ }^{1}$ This work was supported by the National Basic Research Program of China (№_2002 CB 513006) and the National Natural Science Foundation of China (№ 30570928). ${ }^{6}$ Correspondence to Prof Xian-lu ZENG. Phn 86-431-8509-9317.

Fax 86-431-8568-1186.

E-mailzengx779@nenu.edu.cn

Received 2007-07-26

Accepted 2007-11-26

doi: $10.1111 / \mathrm{j} .1745-7254.2008 .00765 . \mathrm{x}$

\begin{abstract}
Aim: To investigate the anti-inflammatory mechanism of the polysaccharides of Ginkgo biloba leaves (PGBL) by inhibiting leucocyte adhesion. Methods: The rough PGBL were isolated and purified. The anti-inflammatory effects of purified PGBL (p-PGBL) were assayed by ear edema induced by xylol and the acute peritonitis model in mice. The effect of p-PGBL on inhibiting the interaction between Pselectin and its ligands was investigated by flow cytometry and flow chamber. Results: p-PGBL could effectively inhibit the acute inflammation in mice and interfere with the adhesion of HL-60 cells, a human leukaemia cell line, or neutrophils to P-selectin in static conditions, as well as the adhesion of neutrophils to Chinese hamster ovary cells expressing human P-selectin and human umbilical vein endothelial cells in flow conditions in a dose-dependant manner. Conclusions: p-PGBL can inhibit the inflammatory process through interfering with the interaction between P-selectin and its ligands.
\end{abstract}

\section{Introduction}

Inflammation is a self-protective process under physiological conditions, but an extreme inflammatory reaction can result in the immune damage of organisms and cause pathological situations. A hallmark of inflammation is the adhesion of leucocytes to vascular endothelial cells (VEC) ${ }^{[1]}$. The binding of adhesion molecules expressed on leucocytes and VEC to their ligands is the critical molecular mechanism for this reaction ${ }^{[2,3]}$.

Selectin is one of the cell adhesion molecule families that mediate the adhesion of leucocytes to VEC, leucocytes to leucocytes, and leucocytes to platelets during inflammation. There are 3 kinds of selectins: P-, L-, and E-selectin, which function in different phases of cell adhesion ${ }^{[3]}$. P-selectin, a transmembrane glycoprotein expressed on the surface of activated platelets and VEC, acts as a receptor to mediate the initial adhesion of leucocytes ${ }^{[4]}$. In vivo, P-selectin antibodies can block leucocyte rolling and adhesion in venules and accumulating in tissues, and P-selectin-deficient mice exhibit severely diminished leucocyte rolling and delayed recruit- ment of leucocytes in various inflammatory tissues. As a result, the antagonists that block or interfere with the role of P-selectin may affect the inflammatory process ${ }^{[5-7]}$.

In the past decade, several P-selectin antagonists have been developed, including $\mathrm{mAb}, \mathrm{sLe}^{\mathrm{x}}$, $\mathrm{sLe}^{\mathrm{a}}$, heparin, as well as its mimetics. Although these antagonists have been shown to be effective in inhibiting P-selectin-mediated leucocyte adhesion and inflammation, they also exhibit various drawbacks, such as narrow cross-reactivity, weak affinity, and a short circulating half-life ${ }^{[8,9]}$. Currently, much work has been focused on finding better inhibitors to prevent abnormal leucocyte emigration ${ }^{[10,11]}$. Polysaccharides of Ginkgo biloba leaves (PGBL) are active components with multiple pharmacological functions, such as oxyradical and hydroxy radical clearance effects, anti-aging properties, antitumor activities, and immunomodulatory effects ${ }^{[12-14]}$. Rough PGBL have been reported to have anti-inflammatory effects, yet the mechanism remains unclear ${ }^{[15]}$. In this paper, we investigated the role and mechanism of purified PGBL (p-PGBL) on anti-inflammation and found that p-PGBL can 
inhibit P-selectin-mediated leucocyte adhesion and inflammation.

\section{Materials and methods}

Animals and cells BALB/c mice (5-6 weeks old) were purchased from the Experimental Research Center of Medical Animals in Changchun (China). Chinese hamster ovary (CHO) cells and HL-60 cells, a human leukaemia cell line, were bought from the Institute of Biochemistry and Cell Biology, Shanghai Institutes for Biological Sciences, Chinese Academy of Sciences (Shanghai, China). The CHO cells were cultured in Iscove's Modified Dulbecco's Medium (IMDM) and the HL-60 cells were cultured in RPMI1640 medium at $37{ }^{\circ} \mathrm{C}$ in the presence of $5 \% \mathrm{CO}_{2}$, and they were all supplemented with $10 \%$ inactivated fetal calf serum (FCS). Human neutrophils were isolated according to the Ficoll density gradient centrifugation method and maintained in RPMI-1640 medium without FCS. Human umbilical vein endothelial cells (HUVEC) were isolated by collagenase treatment as described previously ${ }^{[16,17]}$. HUVEC were passaged by mild trypsinization ( $0.25 \%$ trypsin/0.02 EDTA) and cultured to confluence in $1 \%$ gelatin-coated $35 \mathrm{~mm}$ culture dishes. Before use in the adhesion assays, HUVEC were stimulated with $1 \mathrm{U} / \mathrm{mL}$ human thrombin for $10 \mathrm{~min}$ to obtain maximal levels of P-selectin expression ${ }^{[18]}$.

Proteins and antibodies Recombinant human P-selectin/ Fc chimera protein $(\mathrm{P}-\mathrm{Fc})$ and blocking $\mathrm{mAb}$ to $\mathrm{P}$-selectin (9E1) were obtained from R\&D Systems (Minneapolis, Minnesota, USA). A non-blocking mAb to P-selectin (AC1. 2) was purchased from BD PharMingen (Franklin Lakes, New Jersey, USA). Goat antihuman fluorescein-isothiocyanate (FITC)-labeled immunoglobulin G (IgG) and goat antimouse IgG were purchased from Jackson Immuno-Research Laboratories (West Grove, Pennsylvania, USA). Collagenase and human thrombin were purchased from Sigma-Aldrich (St Louis, Missouri, USA).

Other reagents Sephadex G-75 was obtained from Pharmacia (North Peapack, New Jersey, USA). Thioglycollate broth was obtained from Sigma-Aldrich (USA). All other chemicals were of analytical grade.

Isolation and purification of PGBL Ginkgo biloba leaves were collected from Dandong, Liaoning Province. The PGBL were extracted from fresh Ginkgo biloba leaves according to routine methods ${ }^{[19]}$. To achieve p-PGBL, the PGBL were frozen and thawed repeatedly, ultrafiltrated by 30000 ultrafiltration membranes, and freeze-dried. The powder was fractionalized by gel chromatography on a Sephadex G-75 column $(4 \mathrm{~cm} \times 80 \mathrm{~cm})$ and collected by an automatic fraction collector (BS-100A,Shanghai Huxi Analysis Instrument Fac- tory Co. LTD, Shanghai, China). Then the fraction with the highest peak on the distribution curve was dialyzed, concentrated, and freeze-dried to obtain p-PGBL. p-PGBL purity was measured by gel chromatography on a Sephadex G-75 column $(1.5 \mathrm{~cm} \times 95 \mathrm{~cm})$ and HPLC, respectively. All gel chromatography was monitored with the phenol-sulfuric acid method. The molecular weight of p-PGBL was calculated according to the calibration curve obtained by using various standard dextrans. Nucleotides and proteins in p-PGBL were inspected by a UV spectrum assay. Optical rotation was measured with a WZZ-T 1 polarimeter (Shanghai Physical Optics Instrument, Shanghai, China). The polysaccharide component was determined by gas chromatography $(\mathrm{GC})^{[20]}$.

Preparation of CHO cells expressing human P-selectin Full-length human P-selectin cDNA, subcloned in a pcDNA 3.1 (-) vector, was a kind gift from Dr Spertini O (Centre Hospitalier Universitaire Vaudois, Lausanne Switzerland). The cDNA was 2500 base pairs in length, and were inserted in pcDNA3.1 (-) plasmids at the EcoRV and NotI cloning sites. Then the plasmids were transfected by an electroporation apparatus ( $160 \mathrm{~V}$; Gene Pulser X cellTM, BIORAD, Hercules, California, USA) into CHO cells, which do not express P-selectin. The transfected $\mathrm{CHO}$ cells were selected with G418, and the monoclones of the cells that steadily expressed human P-selectin were selected for the cell adhesion experiment under flow conditions ${ }^{[21]}$.

Ear edema in mice induced by xylene The mice (18 22 g) were randomly divided into 5 individual groups with 8 (sex ratio 1:1) in each group. Each group of mice was intraperitoneally injected with $12.5,25$, and $50 \mathrm{mg} / \mathrm{kg}$ p-PGBL or 2 $\mathrm{mg} / \mathrm{kg}$ dexamethasone (negative control) or $2 \mathrm{mg} / \mathrm{kg}$ sterile saline (positive control), respectively, and the injection interval was $12 \mathrm{~h}$. Thirty minutes after the third injection, a topical edema was induced in each mouse by applying 0.05 $\mathrm{mL}$ xylene to both sides of the right ear of each mouse. The mice were killed by luxation method $0.5 \mathrm{~h}$ after inflammation was developed, and an $8 \mathrm{~mm}$ diameter round slice was cut from the same sites of both ears by using a perforator. The slices were then weighed. The edema level was assessed in terms of the increase in the weight of the right ear piece over that of the left ear. The mean of the difference between the right and left ears was determined for each group. The inhibition percentages were calculated by comparison with the positive control group that only received the xylene application but none of the treatment ${ }^{[15,22]}$.

Thioglycollate-induced peritoneal inflammation In each experimental test, the male mice were randomly separated into 6 individual groups and intraperitoneally injected with 2 
$\mathrm{mL}$ of $3 \%$ thioglycollate broth or sterile pyrogen-free saline. Five minutes later, the mice were intravenously injected with $0.2 \mathrm{~mL}$ of either sterile pyrogen-free saline or different concentration of p-PGBL. The mice were killed after $3 \mathrm{~h}$, and their peritoneal cavities were lavaged with $2 \mathrm{~mL}$ phosphatebuffered saline (PBS $)^{[18]}$. One part of the total peritoneal cells was double-blindly counted with a hemocytometer, while the other part of the cells was fixed and stained with WrightGiemsa. Neutrophils were counted under a microscope (1520 counts/slide for a total of 800 cells) and neutrophils $/ \mathrm{mL}$ were calculated.

Flow cytometric assays For the cell surface P-selectin binding assay, P-Fc $(0.3 \mu \mathrm{g})$ was pre-incubated with PBS supplemented with $1 \mathrm{mmol} \mathrm{CaCl}_{2}$ and $1 \mathrm{mmol} \mathrm{MgCl}_{2}, \mathrm{mAb}$ 9E1, or different concentration of p-PGBL at $37^{\circ} \mathrm{C}$ for $30 \mathrm{~min}$. Then $100 \mu \mathrm{L}$ HL- 60 cells or human neutrophils $\left(5 \times 10^{9} / \mathrm{L}\right)$ were added and the mixture was incubated at $4{ }^{\circ} \mathrm{C}$ for $30 \mathrm{~min}$. After incubation, the cells were washed once, resuspended in 100 $\mu \mathrm{L}$ RPMI-1640 medium containing FITC-labeled goat antihuman $\operatorname{IgG}(2 \mathrm{mg} / \mathrm{L})$, and incubated at $4{ }^{\circ} \mathrm{C}$ for another 30 min. The cells were then washed twice, and 10000 cells were counted for flow cytometric analysis with a FACScan (Becton Dickinson, Franklin Lakes, New Jersey, USA ${ }^{[18]}$.

Flow chamber assays $\mathrm{CHO}$ cells, $\mathrm{CHO}$ cells expressing human P-selectin (CHO-P), and HUVEC $\left(4 \times 10^{8} / \mathrm{L}\right)$ were seeded in $35 \mathrm{~mm}$ culture dishes, respectively, to allow cell monolayers to form. Then $\mathrm{mAb} 9 \mathrm{E} 1$ and different concentration of p-PGBL were added, separately. After the cells were incubated in a $\mathrm{CO}_{2}$ incubator for $30 \mathrm{~min}$, the dishes were assembled in a parallel-plate flow chamber (GlycoTech, Rochville, MD, USA) and mounted on the objective table of an inverted microscope (Olympus Optical, Tokyo, Japan). After washing the flow chamber with Dulbecco's PBS containing $0.1 \%$ bovine serum albumin for $2 \mathrm{~min}, 2 \times 10^{9} / \mathrm{L}$ human neutrophils were perfused through the chamber at a appropriate flow rate to obtain wall shear stress of $0.12 \mathrm{~Pa}$ at $22{ }^{\circ} \mathrm{C}$ by using a syringe pump (Cole-Parmer Instrument Company, Vernon Hills, Illinois, USA), thereby mimicking the fluid mechanical environment of the microcirculation and postcapillary venules. After the appearance of the neutrophils, the field was randomly selected and recorded via the camera (Panasonic, Yokohama, Japan) connected to the inverted microscope. The video was later transferred to a computer. Each sample had 3 dishes, and each dish was measured for $3 \mathrm{~min}$. The mean value was calculated from 3 trials. The number of neutrophils attached to $\mathrm{CHO}$ cells, CHO-P cells, and HUVEC per unit time and area was manually determined by reviewing the videos. The relative adhesion rate of the different concentration of $\mathrm{p}$-PGBL was calculated $^{[18,23]}$.

Statistical analysis Data were expressed as the mean \pm SEM. The statistical significance of differences between means was determined by ANOVA. If the means were shown to be significantly different, multiple comparisons by pairs were performed with the Tukey test. Probability values of $P<0.05$ or $P<0.01$ were selected to be statistically significant.

\section{Results}

PGBL extraction and purification Water-soluble brown-white powder was isolated from Ginkgo biloba leaves and the yield rate was $8.6 \%$. The white powder (pPGBL) was obtained by deproteinization, ultrafiltration and gel chromatography on a Sephadex G-75 column and freezedried. The purity of p-PGBL was confirmed by gel chromatogram on a Sephadex G-75 column and HPLC, and showed that the symmetrical peak that appeared at 16.54 min was consistent with the PGBL peak that had the highest polysaccharide content (Figure 1). An absorption spectrum at 260-280 nm was not detected by the UV spectrum assay, indicating that neither nucleotides nor proteins were presented in p-PGBL. According to the standard curve, the relative molecular weight of p-PGBL was $\sim 10 \mathrm{kDa}$, and the puritywas $98.8 \%$. Optical rotation was $(a)^{20}=+43$. Analyzed by GC, the monosaccharide composition was Gal, Man, Glu, Ara, Rha and galacturonic, and the molar ratio was $6: 2.4: 1.7: 4.6: 6.8: 1$.

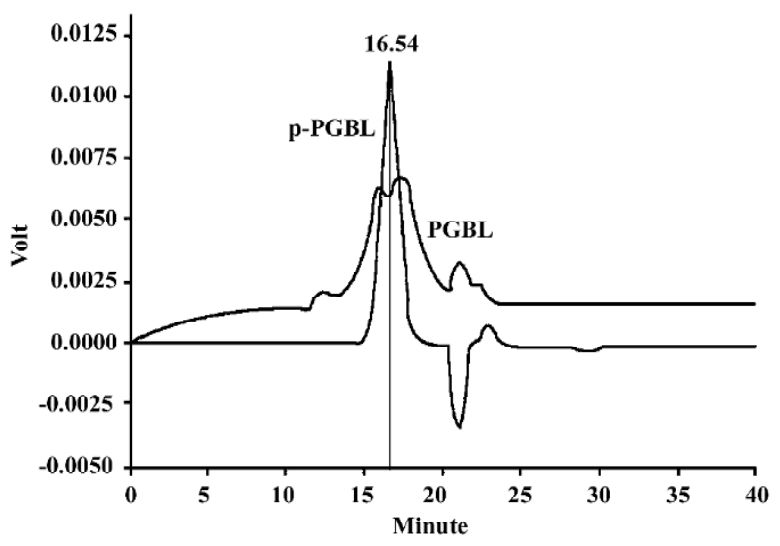

Figure 1. The HPLC of PGBL and p-PGBL PGBL $(200 \mathrm{mg})$ was applied to a column of Sephadex G-75. All of the tubes with $10 \mathrm{~mL}$ fractions were collected with a BS-100A automatic fraction collector. The fractions (p-PGBL) and PGBL were respectively analyzed by HPLC. Instrument: SHIMADZU, Japan, LC-10AT ${ }_{\mathrm{VP}}$; Chromatographic column: TSK-GEL, $\mathrm{G}_{3000 \mathrm{PW}}, 7.8 \mathrm{~mm} 30.0 \mathrm{~cm}$; Mobile phase: $0.9 \% \mathrm{NaCl}$; RF: $0.5 \mathrm{~mL} / \mathrm{min}$; T: $40^{\circ} \mathrm{C}$; Pressure: $1.6 \mathrm{mPa}$; Sample: $20 \mu \mathrm{L}$. The results are the overlaps of PGBL and p-PGBL diagrams. 
p-PGBL inhibits acute inflammation in mice To investigate the anti-inflammatory effect of p-PGBL, the acute inflammation model of ear edema in mice induced by xylene was first used in our experiment. As shown in Figure 2A, the ear edema in mice could be inhibited by p-PGBL at concentrations of $12.5,25$, and $50 \mathrm{mg} / \mathrm{kg}$. Compared with the positive control mice (the sterile saline-injected mice), the inhibition rates of p-PGBL were $36.8 \%, 56.09 \%$, and $64.27 \%$, respectively. The inhibition effect of the p-PGBL was dose dependent. Then we further investigated the anti-inflammatory effect of p-PGBL by using the well-established acute peritonitis model in mice. The results showed that the thioglycollate injection greatly increased the neutrophils in the peritoneal cavity. Compared with the positive control mice (the thioglycollate-injected mice), 5 and $25 \mathrm{mg} / \mathrm{kg} \mathrm{p}$ PGBL could inhibit thioglycollate-induced neutrophil transmigration with an inhibition rate of $46.43 \%$ and $78.11 \%$, respectively, and $50 \mathrm{mg} / \mathrm{kg} \mathrm{p}$-PGBL could entirely block thioglycollate-induced neutrophil transmigration (Figure 2B). The data suggest that p-PGBL has obvious inhibitory effects on acute inflammation, and p-PGBL can alleviate acute inflammation through inhibiting neutrophil transmigration in a dose-dependent manner.

p-PGBL inhibits P-selectin binding to leucocytes in static conditions In acute inflammation, leucocyte transmigration is a multistep process, and P-selectin plays a critical role in the initial leucocyte rolling and adhesion to endothelial cells. Many studies have shown that the binding of P-selectin to its ligands could be inhibited by several natural carbohydrates $^{[8,24,25]}$. To assess whether the effects of p-PGBL on leucocyte transmigration in acute inflammation are due to the inhibition of the interaction of P-selectin with its ligands, we performed adhesion assays using HL-60 cells, which are human leukemic cells expressing P-selectin ligand, and human neutrophils by flow cytometry. As shown in Figure 3A and $3 \mathrm{~B}, \mathrm{P}$-selectin bound to HL-60 or neutrophils steadily, and human P-selectin blocking mAb (9E1) could entirely block the binding. At the concentrations of $0.1 \mathrm{~g} / \mathrm{L}$ and 0.5 $\mathrm{g} / \mathrm{L}, \mathrm{p}-\mathrm{PGBL}$ exhibited a strong inhibitory effect on P-selectin binding. The results confirmed the involvement of P-selectin in acute inflammation and indicated that p-PGBL could inhibit P-selectin binding to its ligands.

p-PGBL inhibits neutrophil adhesion to CHO-P To further investigate the molecular mechanisms of the anti-inflammatory activity of p-PGBL, CHO-P cells steadily expressing human P-selectin (Figure 4A) and CHO-P monolayers cultured in a $35 \mathrm{~mm}$ plate (Figure $4 \mathrm{~B}$ ) were prepared to mimic the activated VEC. Then the inhibitory effect of $\mathrm{p}$-PGBL was examined under a condition that was close to the physi-
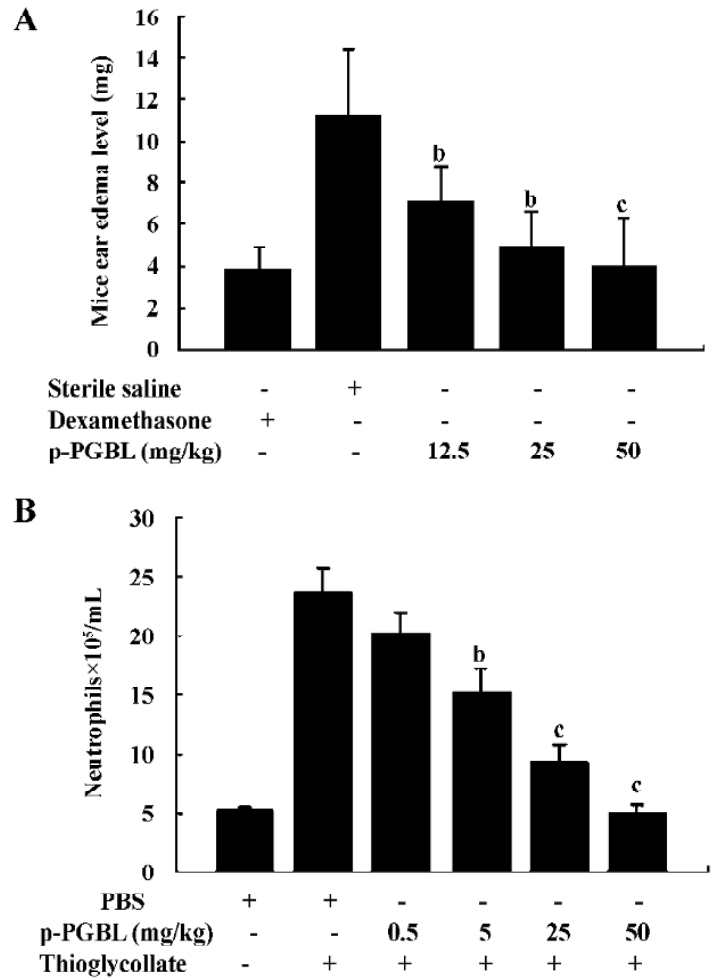

Figure 2. Inhibition of mice acue inflammation by p-PGBL (A) The p-PGBL of $12.5,25$, and $50 \mathrm{mg} / \mathrm{kg}$, dexamethasone (-) or sterile saline (+) at doses of $2 \mathrm{mg} / \mathrm{kg}$ were intraperitoneally injected, respectively. After $30 \mathrm{~min}$, xylene of $0.05 \mathrm{~mL}$ was evenly applied right ear to induced mice ear edema. Other $30 \mathrm{~min}$ later, the mice were sacrificed and $8 \mathrm{~mm}$ diameter ears slice of mice was cut and weighed. The edema level was calculated as described in the Material and Methods. Data are expressed as mean \pm SEM. $n=8$. (B) Acute peritonitis was induced by intraperitoneal injection of thioglycollate $(+)$. After $5 \mathrm{~min}$, p-PGBL was injected intravenously at the concentrations of $0.5,5,25$, and $50 \mathrm{mg} / \mathrm{kg}$ respectively and PBS injection was performed as control. The number of neutrophils in the peritoneal cavity was measured as described in the Material and Methods. Data are expressed as mean \pm SEM. $n=5-10$. The all statistical significance was determined by ANOVA. ${ }^{\mathrm{b}} P<0.05,{ }^{\mathrm{c}} P<0.01$ compared with positive control.

ological blood flow rate $(0.12 \mathrm{~Pa})$. As illustrated in Figure $4 \mathrm{C}$, p-PGBL exhibited a strong inhibitory effect on neutrophils rolling and adhesion to CHO-P cells at the concentrations of $0.1 \mathrm{~g} / \mathrm{L}$ and $0.5 \mathrm{~g} / \mathrm{L}$. Compared with the positive control, the inhibitory rates of p-PGBL at the concentrations of $0.1 \mathrm{~g} / \mathrm{L}$ and $0.5 \mathrm{~g} / \mathrm{L}$ were $71.38 \%$ and $87.61 \%$, respectively. These findings indicate that under a physiological blood flow rate, p-PGBL can inhibit P-selectin-mediated leucocyte adhesion in a dose-dependent manner.

p-PGBL inhibits neutrophil adhesion to HUVEC VEC, when stimulated or activated, can express P-selectin to mediate leucocyte adhesion ${ }^{[2,26]}$. To investigate the anti- 
A

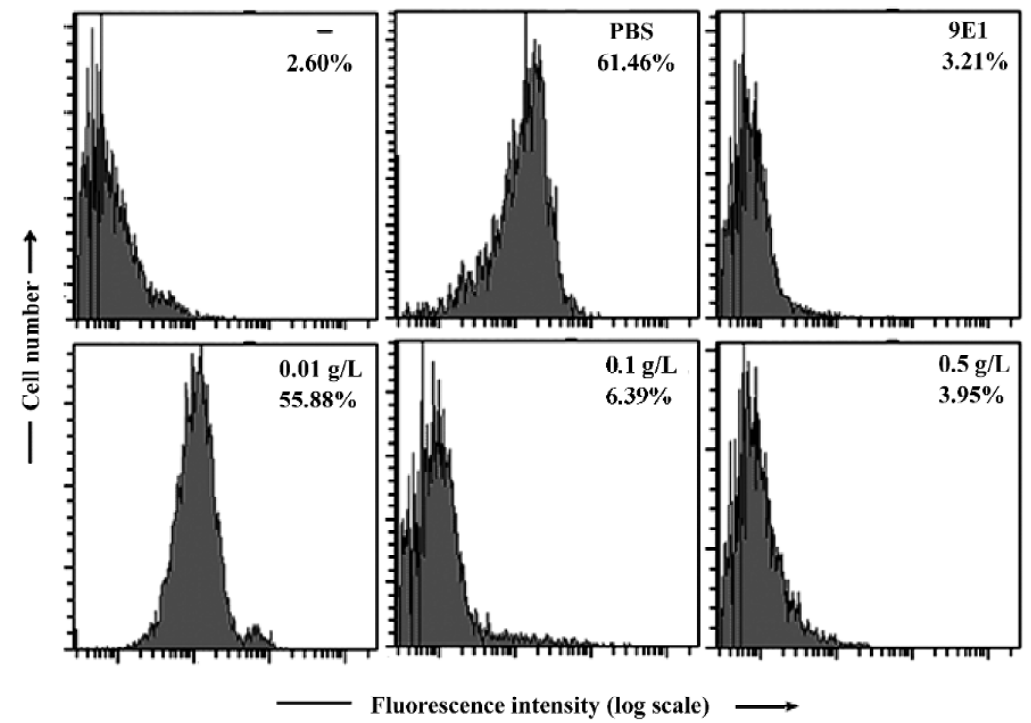

B

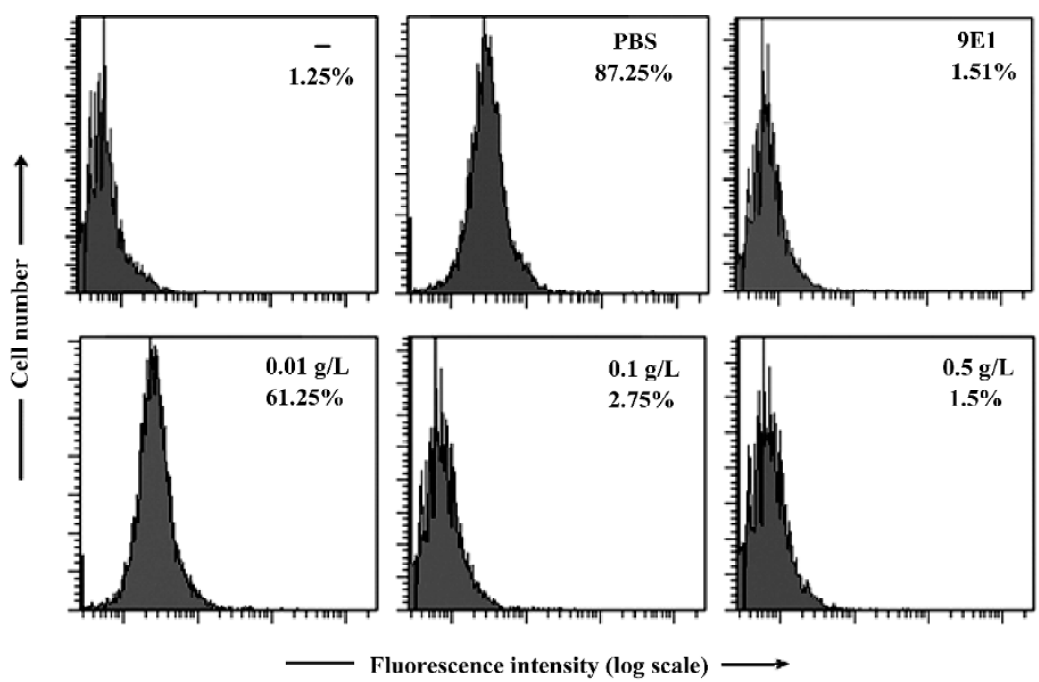

Figure 3. Inhibition of P-selectin binding to HL-60 cells and neutrophils by p-PGBL P-Fc was preincubated with p-PGBL ( $0.01,0.1$, and $0.5 \mathrm{~g} / \mathrm{L}$ ), PBS (positive control) and blocking mAb 9E1 (negative control) at $37^{\circ} \mathrm{C}$ for $30 \mathrm{~min}$. Then, HL-60 cells (A) and neutrophils (B) were respectively added and followed by a FITC-conjugated $\mathrm{Ab}$ against human IgG at $4{ }^{\circ} \mathrm{C}$ for $30 \mathrm{~min}$. The binding events were analyzed by flow cytometry. The results of the $\log$ fluorescence intensities are representative of three independent experiments. The percentage of positive cells is indicated in each histogram.

inflammatory effect of p-PGBL under physiological conditions, we further examined the interaction of neutrophils and HUVEC. As illustrated in Figure 5, the treatment of HUVEC monolayers (Figure 5A) with human thrombin $(1 \mathrm{U} / \mathrm{mL})$ dramatically increased the number of neutrophil rolling and adhesion to HUVEC, and blocking $\mathrm{mAb}$ to Pselectin (9E1) partly inhibited neutrophil rolling and adhesion; p-PGBL, at the concentrations of $0.1 \mathrm{~g} / \mathrm{L}$ and 0.5 $\mathrm{g} / \mathrm{L}$, dramatically inhibited the rolling and adhesion. These results showed that the inhibition of p-PGBL in neutrophil adhesion to HUVEC is mainly P-selectin mediated.

\section{Discussion}

Plant polysaccharides are natural, non-toxic substances with multiple biological activities. Many plant polysaccharides, such as Radix astragali, Lentinus edodes, and Agaricus blazei Muri, have been shown to possess anti-acute inflammatory effects ${ }^{[27-29]}$. Song et al found that rough PGBL exhibit evident anti-inflammatory activity due to the inhibition of ear swelling and the capillary permeability in 

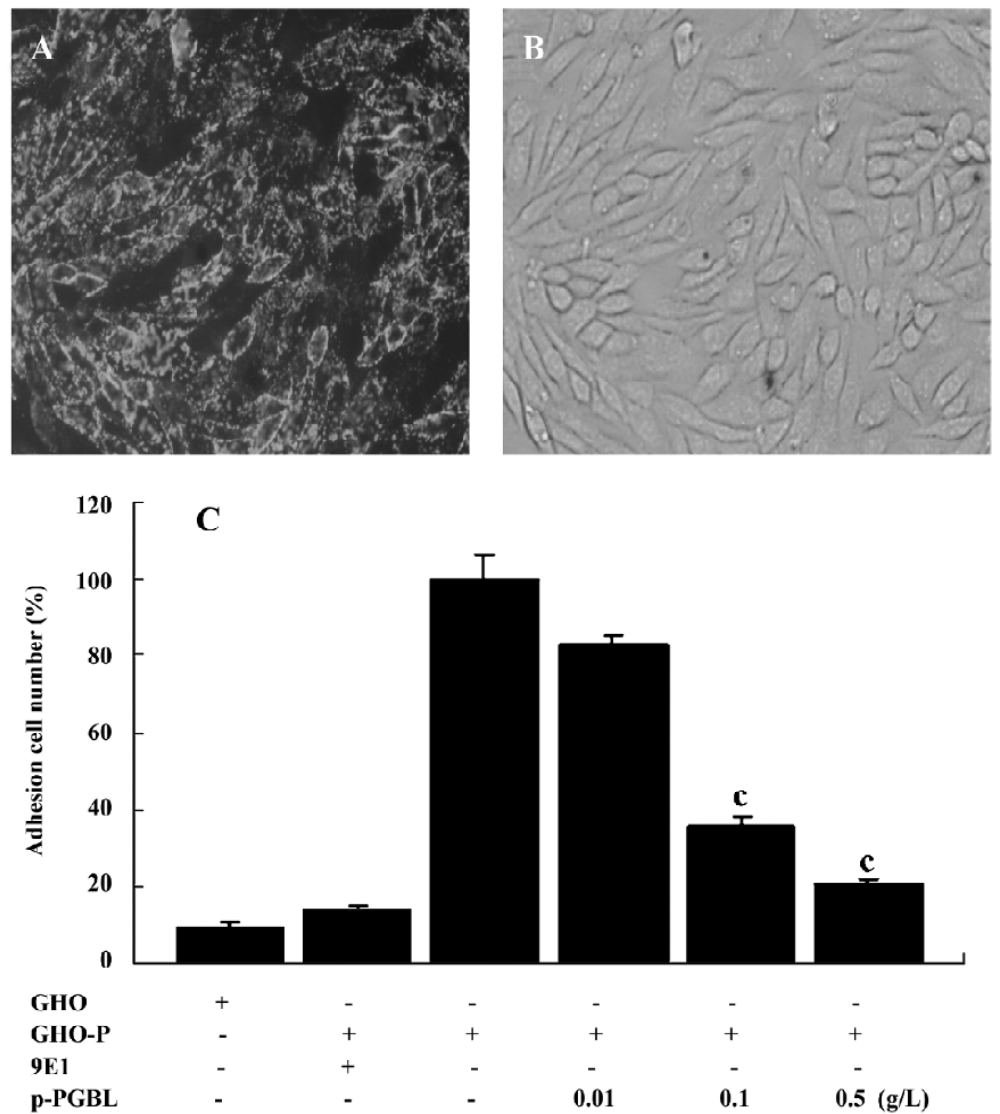

Figure 4. Inhibition of the adhesion of neutrophils to CHO-P by p-PGBL (A) CHO-P cells steadily expressing human P-selectin were prepared by electroporation apparatus and G418 selection. (B) CHO-P monolayer was obtained by culturing CHO-P cells in 35 mm plate. (C) The flow chamber experiment was performed, and the adhesion of neutrophils to CHO cells $(-)$ or $\mathrm{CHO}-\mathrm{P}$ cells $(+)$ at the flow rate of $0.12 \mathrm{~Pa}$ was measured by video-microscopy. For inhibition experiments, CHO-P cells were respectively preincubated with $9 \mathrm{E} 1$ (blocking mAb to Pselectin) or p-PGBL of $0.01,0.1$, and $0.5 \mathrm{~g} / \mathrm{L}$. Controls were run before and after each assay. All values were expressed as the mean \pm SEM. and calculated as percentages of the positive control. The results are representative of 3-6 separate experiments. The statistical significance was determined by ANOVA. ${ }^{\mathrm{b}} P<0.05,{ }^{\mathrm{c}} P<0.01$ compared with positive control. (A, B $\times 100$ magnification).

mice, but the mechanism has not been clearly understood as yet $^{[15]}$. In the present study, the rough PGBL was further purified by gel chromatography, and the purified fraction was found to have a uniform molecular weight (Figure 1). The anti-inflammatory effect of p-PGBL was detected by examining the ear edema in mice and peritoneal transmigration of neutrophils in the mouse acute inflammatory model. We found that $\mathrm{p}-\mathrm{PGBL}$ could significantly decrease ear edema in mice and peritoneal deposition of neutrophils in a dose-dependent manner (Figure 2A, 2B). Compared with the findings of Song et al, our p-PGBL could preserve better antiinflammatory activity even at a lower concentration due to the inhibition of ear edema and the blockage of neutrophil transmigration.

It has been widely reported that P-selectin plays a critical role in initial leucocyte rolling and adhesion to endothelial cells on the inflammatory sites by interacting with its major ligand PSGL- ${ }^{[30,31]}$. Any antagonist that can block the interaction of P-selectin and its ligands is likely to be effective in inhibiting the inflammatory process ${ }^{[32,33]}$. Here, we showed that p-PGBL can effectively block the interaction between Pselectin and HL-60 cells or neutrophils (Figure 3A, 3B), implying that the inhibitory effect of p-PGBL in anti-inflammation is mainly due to the interference of P-selectin binding to its ligands. This observation was further confirmed with CHO-P and HUVEC cells by the flow chamber assay conducted under physiological conditions (Figures 4,5).

Leukocyte recruitment during acute and chronic inflammatory responses is a multistep process regulated by a variety of adhesion molecules and inflammatory factors ${ }^{[34]}$. In in vitro experiments, we found that $\mathrm{P}$-selectin blocking $\mathrm{mAb}$ (9E1) almost totally blocked the adhesion of neutrophils to 
$\mathbf{A}$

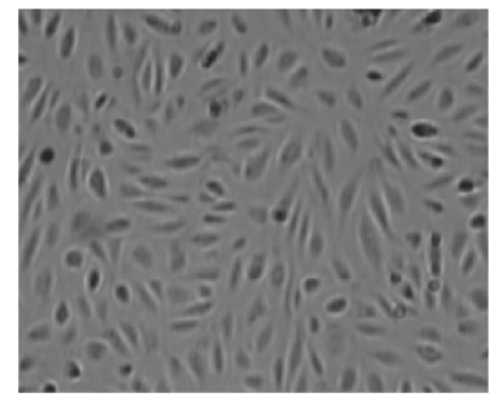

B

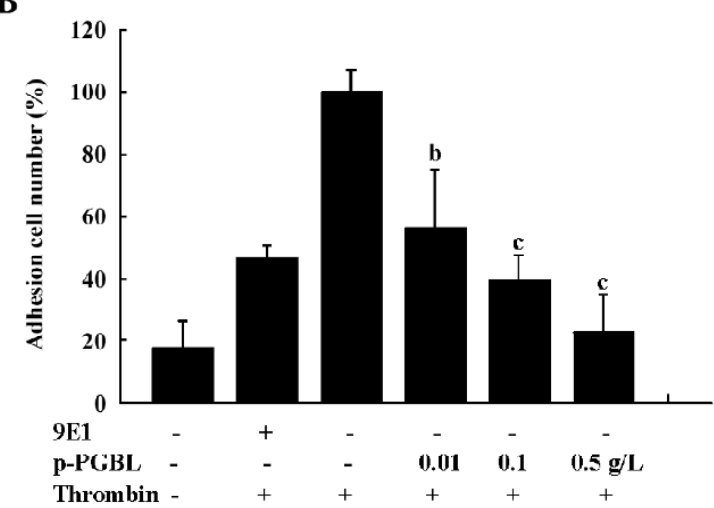

Figure 5. Inhibition of the adhesion of neutrophils to HUVEC by p-PGBL The adhesion experiments were performed as described in Materials and Methods. (A) HUVEC monolayers in $35 \mathrm{~mm}$ plate was obtained as described in Materials and Methods. (B) For inhibition assay, HUVEC monolayers were pretreated with $9 \mathrm{E} 1$ or the different concentrations of p-PGBL $(0.01,0.1$, and $0.5 \mathrm{~g} / \mathrm{L})$ or PBS. Values are calculated as percentages of the positive control (with thrombin, but no inhibitor) and expressed as the mean \pm SEM. Statistical significance of differences between means was determined by ANOVA. ${ }^{\mathrm{b}} P<0.05,{ }^{\mathrm{c}} P<0.01$ compared with positive control. (A $\times 100$ magnification)

CHO-P, but only partly blocked the adhesion of neutrophils to HUVEC (Figures 4C,5B), implying that other adhesion molecules on HUVEC also functioned in the rolling process. Our results also showed that p-PGBL could more effectively block the adhesion of neutrophils to HUVEC than P-selectin blocking $\mathrm{mAb}$, suggesting that, besides P-selectin, p-PGBL also interfered with the interactions of other adhesion molecules or inflammatory factors in this process. These results were also confirmed by the ear edema in mice and acute peritonitis experiments in vivo (Figure 2A,2B). We also found that at a concentration of $0.01 \mathrm{~g} / \mathrm{L}, \mathrm{p}-\mathrm{PGBL}$ could effectively inhibit neutrophil adhesion to HUVEC in vitro (Figure $5 \mathrm{~B}$ ), but the inhibitory effects of p-PGBL on neutrophil transmigration in vivo was not obvious at the concentration of 0.5 $\mathrm{mg} / \mathrm{kg}$, approximating to $0.01 \mathrm{~g} / \mathrm{L}(1 \mathrm{~mL}$ blood $/ 20 \mathrm{~g}$ weight mouse; Figure $2 \mathrm{~B})$. These results indicated that a higher concentration of $\mathrm{p}$-PGBL is required for inhibiting neutro- phil transmigration and inflammation in vivo.

Inflammation can be divided into specific and nonspecific. At present, we still have not obtained better drugs to treat non-specific inflammation. Although some drugs, such as hormones, have been effective in treating non-specific inflammation diseases, they exhibited strong side-effects. As a natural, non-toxic substance, p-PGBL has demonstrated its effect in inhibiting neutrophil transmigration and inflammation in vivo. We believe that p-PGBL is a promising drug for the clinical application of non-specific inflammation diseases by offering higher efficiency and reducing side-effects.

\section{Acknowledgements}

Special thanks to Jing-feng YANG and Prof Zhong-yan LIANG from the Normal University of Northeast China for their technical support on the polysaccharide extraction from the Ginkgo biloba leaves.

\section{References}

1 Steeber DA, Tedder TF. Adhesion molecule cascades direct lymphocyte recirculation and leukocyte migration during inflammation. Immunol Res 2000; 22: 299-317.

2 Ley K, Reutershan J. Leucocyte-endothelial interactions in health and disease. Handb Exp Pharmacol 2006; 176: 97-133.

3 Ley K. The role of selectins in inflammation and disease. Trends Mol Med 2003; 9: 263-8.

4 McEver RP. Properties of GMP-140, an inducible granule membrane protein of platelets and endothelium. Blood Cells 1990; 16: $73-83$.

5 Ludwig RJ, Schön MP, Boehncke WH. P-selectin: a common therapeutic target for cardiovascular disorders, inflammation and tumour metastasis. Expert Opin Ther Targets 2007; 11: 110317.

6 Lorant DE, Topham MK, Whatley RE, McEver RP, McIntyre $\mathrm{TM}$, Prescott SM, et al. Inflammatory roles of P-selectin. J Clin Invest 1993; 92: 559-70.

7 Jung U, Ley K. Mice lacking two or all three selectins demonstrate overlapping and distinct functions for each selectin. J Immunol 1999; 162: 6755-62.

8 Wang L, Brown JR, Varki A, Esko JD. Heparin's anti-inflammatory effects require glucosamine 6-O-sulfation and are mediated by blockade of L- and P-selectins. J Clin Invest 2002; 110: 12736 .

9 Watson SR, Fennie C, Lasky LA. Neutrophil influx into an inflammatory site inhibited by a soluble homing receptor-IgG chimera. Nature 1991; 349: 164-7.

10 Bendas G. Inhibitors of membrane receptors involved with leucocyte extravasation. Mini Rev Med Chem 2005; 5: 575-84.

11 Ushakova NA, Preobrazhenskaya ME, Bird MI, Priest R, Semenov AV, Mazurov AV, et al. Monomeric and multimeric blockers of selectins: comparison of in vitro and in vivo activity. Biochemistry (Mosc) 2005; 70: 432-9.

12 Jin JQ, Ding DN, Bian XL. The study of chemical and scaveng- 
ing action to hydroxyl free radical of polysaccharides of Ginkgo biloba leaf. J Xi'an Med Univ 2000; 21: 417-9 (in Chinese).

13 Liu X, Shen F, Yang XL. Effect of PLGB on activity of immune cell in mice. J Shenyang Med Coll 1999; 1: 140-2 (in Chinese).

14 Chen Q, Liu TJ. Studies on immunomodulatory and antineoplastic activities of polysaccharide isolated from Ginkgo biloba leaf (GBLP). Pharmacol Clin Chin Mat Med 2003; 19: 18-9 (in Chinese).

15 Song LY, Ma WX, Yu RM, Kan QM, Yao XS. Studies on the biological activities of polysaccharides from the cell cultures and the leaves of Ginkgo Biloba. Chin J Biochem Pharm 1999; 20: 278-80 (in Chinese).

16 Jaffe EA, Nachman RL, Becker CG, Minick RC. Culture of human endothelial cells derived from umbilical vein. J Clin Invest $1973 ; 52: 2745$.

17 Kasper B, Brandt E, Ernst M, Petersen F. Neutrophil adhesion to endothelial cells induced by platelet factor 4 requires sequential activation of Ras, Syk, and JNK MAP kinases. Blood 2006; 107: 1768-75.

18 Gao YG, Li N, Fei R, Chen ZH, Zheng S, Zeng XL. P-selectinmediated acute inflammation can be blocked by chemically modified heparin, RO-heparin. Mol Cells 2005; 19: 350-5.

19 Kraus J. Water-soluble polysaccharides from Ginkgo biloba leaves. Phytochemistry 1991; 30: 301-2.

20 Wang ZJ, Luo DH, Liang ZY. Structure of polysaccharides from the fruiting body of Hericium erinaceus pers. Carbohyd Polym 2004; 57: 241-7.

21 Mathieu S, El-Battari A. Monitoring E-selectin-mediated adhesion using green and red fluorescent proteins. J Immunol Methods 2003; 272: 81-92.

22 Zhang P, Ding DL, Zhang H, Liu PL, Liu W, Zhang R, et al. Study on anti-inflammatory and analgesic effects of arsenous acid injection. J Harbin Med Univ 2004; 38: 531-6.

23 Yeo EL, Sheppard JI, Feuerstein IA. Role of P-selection and leucocyte activation in polymorphonuclear cell adhesion to sur- face adherent activated platelets under physiologic shear conditions (an injury vessel wall model). Blood 1994; 83: 2498-507.

24 Lasky LA. Selectin: interpreters of cell specified carbohydrate information during inflammation. Science 1992; 258: 964-9.

25 Kansas GS. Selectins and their ligands: current concepts and controversies. Blood 1996; 88: 3259-64.

26 Ruiz-Torres MP, Pérez-Rivero G, Rodríguez-Puyol M, RodríguezPuyol D, Díez-Marqués ML. The leukocyte-endothelial cell interactions are modulated by extracellular matrix proteins. Cell Physiol Biochem 2006; 17: 221-32.

27 Hao Y, Qiu QY, Wu J, Wang YG. Effect of Astragalus polysaccharides in promoting neutrophil-vascular endothelial cell adhesion and expression of related adhesive molecules. Chin J Integr Trad West Med 2004; 24: 427-9 (in Chinese).

28 Zhao RJ, Zhao ZL, Wang D, Li LB, Jin ZN. Anti-inflammatory effects of Agaricus Blazei Murill polysaccharide. J Med Sci Yanbian Univ 2004; 27: 19-22 (in Chinese).

29 Ou-Yang XN, Yu ZY, Wang WW, Zhang X. Trial study on antiinflammatory effects of Lentinan. Acad J PLA Postgrad Med Sch 2006; 27: 56-7 (in Chinese).

30 McEver RP, Cummings RD. Role of PSGL-1 binding to selectins in leukocyte recruitment. J Clin Invest 1997; 100: 485-91.

31 Varki A. Selectin ligands. Proc Natl Acad Sci USA 1994; 91: 7390-7.

32 Kneuer C, Ehrhardt C, Radomski MW, Bakowsky U. Selectins-potential pharmacological targets? Drug Discov Today 2006; 11: 1034-40.

33 Xie X, Rivier AS, Zakrzewicz A, Bernimoulin M, Zeng XL, Wessel $\mathrm{HP}$, et al. Inhibition of selectin-mediated cell adhesion and prevention of acute inflammation by non-anticoagulant sulfated saccharides. Studies with carboxyl-reduced and sulfated heparin and with trestatin a sulfate. J Biol Chem 2000; 275: 34 818-25.

34 Radi ZA, Kehrli ME, Ackermann MR. Cell adhesion molecules, leukocyte trafficking, and strategies to reduce leukocyte infiltration. J Vet Intern Med 2001; 15: 516-29. 